\title{
Effects of clinical use of NiTi reciprocating instruments on cyclic and torsional resistance, and on roughness
}

\section{Edson Jorge Lima MOREIRA(a) Henrique dos Santos ANTUNES ${ }^{(b)}$ (C) Victor Talarico Leal VIEIRA(b) Daniele Moreira CAVALCANTE(a) Henrique Eduardo OLIVEIRA ${ }^{(a)}$ Diogo da Silva OLIVEIRA ${ }^{(a)}$ Gustavo DE-DEUS(a) Emmanuel João Nogueira Leal da SILVA ${ }^{(b)}$ (1)}

(a) Universidade Federal Fluminense - UFF, School of Dentistry, Department of Endodontics, Niterói, RJ, Brazil.

(b) Universidade do Grande Rio - Unigranrio, School of Dentistry, Department of Endodontics, Rio de Janeiro, RJ, Brazil.

Declaration of Interests: The authors certify that they have no commercial or associative interest that represents a conflict of interest in connection with the manuscript.

Corresponding Author:

Emmanuel João Nogueira Leal da Silva

E-mail: nogueiraemmanuel@hotmail.com

https://doi.org/10.1590/1807-3107bor-2021.vol35.0021

Submitted: May 21, 2020

Accepted for publication: October 8, 2020

Last revision: November 9, 2020

\begin{abstract}
The aim of the present study was to evaluate the cyclic fatigue, torsional resistance and surface roughness of Reciproc R25 instruments in four different situations, namely as new instruments and as instruments tested after clinical preparation of one, two or three maxillary molars with four root canals. The total time required to perform each root canal preparation was recorded. Cyclic fatigue resistance was determined by the time to fracture using a customized testing device ( $\mathrm{n}=10$ per group). The torsional test evaluated the torque and angle of rotation to failure according to ISO 3630- 1 ( $n=10$ per group). The roughness of the working parts of new and used instruments was evaluated with a profilometer ( $n=5$ per group). Statistical analysis was performed using one-way ANOVA and Tukey's test. The level of significance was set at $5 \%$. No fractures or deformations were observed after clinical use. Higher preparation time was needed during the third use of the instruments for all root canals $(p<0.05)$. There were no significant differences among the groups in regard to either cyclic fatigue or torsional resistance $(p>0.05)$. Regarding the roughness measurements, groove depth was higher on new and one- versus two- or three-maxillary-molar-prepared instruments $(p<0.05)$. It can be concluded that the clinical use of Reciproc instruments increased preparation time and decreased surface roughness. However, clinical use did not affect the cyclic fatigue or torsional resistance of the Reciproc instruments.
\end{abstract}

Keywords: Dental Instruments; Endodontics; Root Canal Therapy.

\section{Introduction}

Despite the clear advantages of nickel-titanium (NiTi) instruments, they still present some risk of fracture during root canal preparation, even if there may be no visible macroscopic deformations. ${ }^{1,2,3}$ Instrument fractures are caused by cyclic or torsional fatigue. In the first scenario, failure occurs by repetitive cycles of tensile and compressive stress during instrument rotation in curved canals. ${ }^{1}$ In the case of torsional fracture, the elastic limit of the instrument alloy is exceeded, because the instrument binds to the root canal. ${ }^{1}$ Manufacturers have developed several strategies to overcome these problems, such as modifying instrument design, creating new NiTi alloys and using new activation kinematics. ${ }^{4,5,6,7}$ 
The basic concept behind reciprocating kinematics is to have counterclockwise (CCW) and clockwise $(\mathrm{CW})$ movements that are asymmetrical, to produce non-continuous rotation motion. While the rotation in one direction engages the instrument inside the canal for cutting, the opposite rotation (with a lower angle) promotes its disengagement and releases the stress. Today, an extensive body of research posits that instrument fracture can be reduced by changing the kinematics from rotary to reciprocating, without adversely affecting other endodontic outcomes. ${ }^{5,8,9,10}$

One of the first reciprocating NiTi systems introduced in the endodontic market was Reciproc (VDW, Munich, Germany). Reciproc system instruments are manufactured with an M-Wire NiTi alloy and an S-shaped cross-section design, and come in three different sizes: R25 (tip size 25; .08v taper), R40 (tip size 40; .06v taper) and R50 (tip size $50 ; .05 \mathrm{v}$ taper). According to the instructions of the Reciproc manufacturer, this system is a single-use instrument, which can be used in multiple canals of the same tooth and then discarded. However, a recent clinical study pointed out that single-file reciprocating instruments can be used in up to 3 cases of endodontic treatment of posterior teeth, with a low fracture incidence. ${ }^{11}$ This study highlighted that reciprocating instruments such as those providing continuous rotation can be reused safely. Moreover, Generali and colleagues ${ }^{12}$ recently demonstrated that Reciproc cyclic fatigue and torsional resistance were not affected by simulated clinical use in severely curved molars. However, more in-depth knowledge is needed to determine whether clinical use influences the mechanical properties of these instruments. Therefore, the aim of the present study was to evaluate the cyclic fatigue, torsional resistance and roughness of Reciproc R25 instruments in different situations, namely new instruments with no previous clinical use, and instruments tested after the clinical preparation of one, two or three maxillary molars with four root canals. The total time required to perform each root canal preparation was also recorded and compared. The null hypotheses tested were:

a. there are no differences between the cyclic fatigue resistance of new instruments and those prestressed by root canal preparations; b. there are no differences between the torsional resistance of new instruments and those prestressed by root canal preparations;

c. there are no differences in the surface roughness of new instruments versus those prestressed by root canal preparations, and

d. there are no differences in the time needed to perform root canal preparations using new instruments versus those prestressed by root canal preparations.

\section{Methodology}

The study protocol was approved by the local ethics committee (15414019.6.0000.5283). The sample calculation was performed based on previous studies $^{4,7}$ using $G^{*}$ Power v3.1 for Mac (Heinrich Heine, University of Düsseldorf, Düsseldorf, Germany), by selecting $\mathrm{F}$ tests - ANOVA: fixed effects, omnibus, and one-way. An alpha-type error of 0.05 , a beta power of 0.95 and an effect size of 0.80 were used. A total of eight samples per group were indicated as the ideal size required for determining significant differences. However, ten samples per group were used, based on an additional $20 \%$ calculated to compensate for possible outlier values that might lead to sample loss.

One endodontic specialist working routinely with the Reciproc system for over 8 years performed all the clinical procedures. In the present study, 150 first maxillary molars with four separate canals [mesiobuccal canal (MB1), second mesiobuccal canal (MB2), distobuccal canal (DB) and palatal canal $(\mathrm{P})$ ], were selected from patients seeking care for teeth needing endodontic treatment for curative or prosthodontic purposes. Patients having teeth with incomplete root formation, curvatures greater than $45^{\circ}$, calcified canals, canals with a radiographically visible double curvature, and previous endodontic treatment were excluded from the study.

The number of times an instrument would be used was determined using random software available at www.random.org. Numbers 1 through 3 were used to assign instruments to cases as follows: 1: R25 instrument, one use; 2: R25 instrument, two uses; and 3: R25 instrument, three uses. A total of 100 Reciproc R25 instruments were used. 
Root canal preparation was standardized precisely, following the manufacturer's directions for using Reciproc instruments (http://www.vdw-dental.com/ fileadmin/redaktion/downloads/presse/yared_ reciproc_concept_en.pdf). Access was obtained conventionally using burs and ultrasonic tips with sizes compatible with the volume of each pulp chamber. Afterward, the coronal and middle thirds of each root canal were prepared initially based on a working length (WL) estimated from the preoperative radiograph, without any prior glide path. The instrument was activated using 3 in-and-out movements, and was then removed, after which the flutes were cleaned, and the root canals were flushed with $5.25 \%$ sodium hypochlorite. These steps were repeated until the instrument reached the estimated working length of two coronal thirds. The WL was established $1 \mathrm{~mm}$ short of the apical foramen, by using a Mini Root ZX II electronic foraminal locator (J Morita Corp, Fushimi-ku, Kyoto, Japan). Then, the apical third of the root canals was prepared, repeating the same movement until the WL was reached. The instruments were driven by a VDW Silver Reciproc electric motor in "RECIPROC ALL" mode, and a 6:1 handpiece (Sirona Dental Systems $\mathrm{GmbH}$, Bensheim, Germany). Foramen patency was checked with a \#10 K-type file inserted $1 \mathrm{~mm}$ beyond the real length of the tooth, and was maintained during the entire root canal preparation procedure. The palatal root canal was complemented always using a Reciproc R40 instrument.

Irrigating solution was dispensed with a 24-G needle (Max-I-Probe; Dentsply Tulsa Dental, York, USA) during access, and with a 31-G NaviTip needle (Ultradent Products, South Jordan, UT) when the WL was reached and after each instrument insertion. The canals were kept filled with the irrigating solution, which was continuously renewed. A total of $25 \mathrm{~mL} \mathrm{NaOCl}$ was used for each tooth during each procedure.

All the instruments were observed with a dental operating microscope (Opmi Pico; Carl Zeiss, Göttingen, Germany) under $8 \times$ magnification after each use. The following visual criteria were adopted to control how many times the instruments were used ${ }^{11}$ : a. First-use instruments: instruments that were used immediately after removal from the original manufacturer blister, and that still had an intact silicone ring. After first use, these instruments were cleaned in an ultrasonic bath with an enzymatic detergent for 20 minutes. Afterward, they were placed in individual packages and sterilized by autoclaving at $134^{\circ} \mathrm{C}$ for 24 minutes.

b. Second-use instruments: instruments that were removed from the sterilization package and that still had their original silicone ring. Deformation of the ring from the sterilization process identified its second use, and required removal of the ring with a sterile scalpel blade, so that the instrument could be reused. A new sterilization cycle was performed after reuse, as previously described.

c. Third-use instruments: instruments that were in the packaging without the silicone ring after sterilization and before reuse.

At the end of the procedure, the operator completed a questionnaire with information related to the case, including details of any fractures or deformities, such as fractured instruments, fragment size, fracture location, number of uses before fracture, and the success or otherwise of the bypass or fragment removal procedure. In addition, the time during which the instrument remained activated in each canal during root canal preparation and the total time needed to perform the root canal preparation were tabulated and evaluated statistically. After clinical preparation, instruments used once, twice or three times were evaluated statistically regarding their cyclic fatigue, torsional resistance and surface roughness.

\section{Cyclic fatigue test}

The cyclic fatigue test was performed with a custom-made device. The artificial canal was manufactured in a tapered shape, corresponding to the dimensions of the instruments tested. It provided a suitable simulated root canal with a $60^{\circ}$ angle 
of curvature and 5-mm radius of curvature. The center of the curvature was $5 \mathrm{~mm}$ from the tip of the instrument. The upper part of the artificial canal was open and covered with tempered glass to prevent the instruments from slipping out.

Ten instruments from each group (unused, used once, used twice and used three times) were activated with a 6:1 reduction handpiece (Sirona Dental Systems GmbH, Bensheim, Germany) powered by a torque-controlled motor (Silver Reciproc; VDW), using the preset programs for the Reciproc system ("RECIPROC ALL"), as recommended by the manufacturer. The electric handpiece was mounted on a device to allow precise and reproducible placement of each instrument inside the simulated canal. All the instruments were driven following the manufacturer's instructions until a fracture occurred. The instruments reciprocated freely within the simulated canal, which was filled with warm distilled water $\left(37^{\circ} \mathrm{C}\right)$. The simulated canal was submerged in a plastic container filled with water, and an aquarium thermostat was submerged in the water a few minutes to test the water temperature for each instrument, until ultimately reaching the desired temperature $\left(37^{\circ} \mathrm{C}\right)$. The time was recorded and stopped as soon as a fracture was detected visually and/or audibly.

\section{Torsional resistance behavior test}

The torsional load was applied until fracture to estimate the mean ultimate torsional strength and angle of rotation of the tested instruments (n $=10$ for each group: unused, used once, used twice and used three times), by using a custom-made device produced according to ISO 3630-1. ${ }^{13}$ The tests were performed at room temperature $\left(21^{\circ} \mathrm{C}\right)$. Each instrument was clamped at $3 \mathrm{~mm}$ from the tip using a chuck connected to a torque-sensing load cell. Then the shaft of the instrument was fastened by using an opposing chuck that could be rotated with a stepper motor. All the instruments were rotated counterclockwise at a speed of $2 \mathrm{rpm}$ until instrument fracture. The torque load $(\mathrm{Ncm})$ and angular rotation $\left({ }^{\circ}\right)$ were monitored continuously using a torsiometer, and the ultimate torsional strength and angle of rotation at failure were provided by a specifically designed computed program.

\section{Scanning Electron Microscopic (SEM) evaluation}

SEM (JSM 5800; JEOL, Tokyo, Japan) was used to analyze the fracture surfaces of all the tested instruments submitted to the cyclic fatigue and torsional resistance behavior tests, in order to observe the fracture mode. The instruments were cleaned in an ultrasonic cleaning device (Gnatus, Ribeirão Preto, Brazil), in distilled water for 3 minutes before SEM evaluation, and at 250× magnification.

\section{Surface roughness}

The roughness of the working parts of the new instruments and those used once, twice and three times was evaluated by using a New View 7100 Profilometer (Zygo, Middlefield, CT) on 5 instruments from each group. The New View is an interferometric noncontact 3-dimensional surface measurement system. The profiler gives ultraprecise 3-dimensional analyses of any surface, and rapidly measures heights from $0.1 \mathrm{~nm}$ to $1.0 \mathrm{~mm}$, with vertical resolution as low as $0.1 \mathrm{~nm}$. Roughness was quantified at the apical, middle, and coronal thirds of the instruments; 3 measurements were performed for each third in randomly selected areas, for a total of 9 measurements per instrument, according previously published studies. ${ }^{14,15}$ The groove depth value for each instrument was established as the mean of the 9 measurements.

\section{Statistical analysis}

Because the preliminary analysis of the raw pooled and isolated data revealed a bell-shaped distribution (Shapiro-Wilk normality test), statistical analysis was performed by using parametric methods (One-way ANOVA). Post-hoc pairwise comparisons were performed using the Tukey test. The alpha-type error was set at 0.05. SPSS 11.0 (SPSS, Chicago, USA) was used as the analytical tool. 


\section{Results}

No fractures or deformations were observed in any of the instruments after clinical use. The time required to prepare each root canal, and the total time to prepare the entire tooth, according to each group of instruments (used once, twice and three times) are shown in Figure 1. No differences were observed in the time required to prepare the root canals after one or two uses ( $p>0.05)$, except for the MB1 root canal ( $p<0$.05). However, a longer preparation time was needed during the third use of the instruments for all root canals $(\mathrm{p}<0.05)$.

The average and the standard deviation of the results obtained for the cyclic fatigue, torsional resistance and surface roughness evaluations are shown in Table. There were no significant differences between non-used instruments and instruments used in up to 3 maxillary molars, for either cyclic fatigue or torsional resistance tests $(p<0.05)$. SEM visual inspection of the fractured surface indicated similar and typical features of cyclic fatigue and torsional failure for all the tested groups (Figure 2). Regarding the roughness measurements, groove depth was higher for the new and one-molar used instruments than those used to prepare two or three maxillary molars $(p<0.05)$ (Figure 3$)$.

\section{Discussion}

The influence of ex vivo use on Reciproc and Reciproc Blue instrument properties was evaluated by Generali et al. ${ }^{12}$ Nevertheless, a comprehensive literature review found no study evaluating the cyclic fatigue and torsional resistance of Reciproc instruments after clinical use. Although the Reciproc system is considered a single-use instrument by its manufacturer, there is a strong tendency to reuse these instruments, especially for economic reasons. Recently, Bueno et al. ${ }^{11}$ demonstrated low fracture incidence of the Reciproc reciprocating instrument, even after preparing 3 posterior teeth. The fracture incidence found by the Bueno et al. study ${ }^{11}$ was similar to that of the Plotino et al. study, ${ }^{16}$ where Reciproc instruments were single-used. In the present study, even after preparing up to 3 maxillary molars with four root canals, no instrument fracture was observed. Moreover, no macroscopic signs of plastic deformation or spiral distortion were detected in any of the tested instruments. These results corroborate those of Bueno et al., ${ }^{11}$ indicating that the Reciproc instrument can be used safely in up to 3 molars.

In accordance with recent studies, ${ }^{6,12}$ a static model has been devised using a custom-made

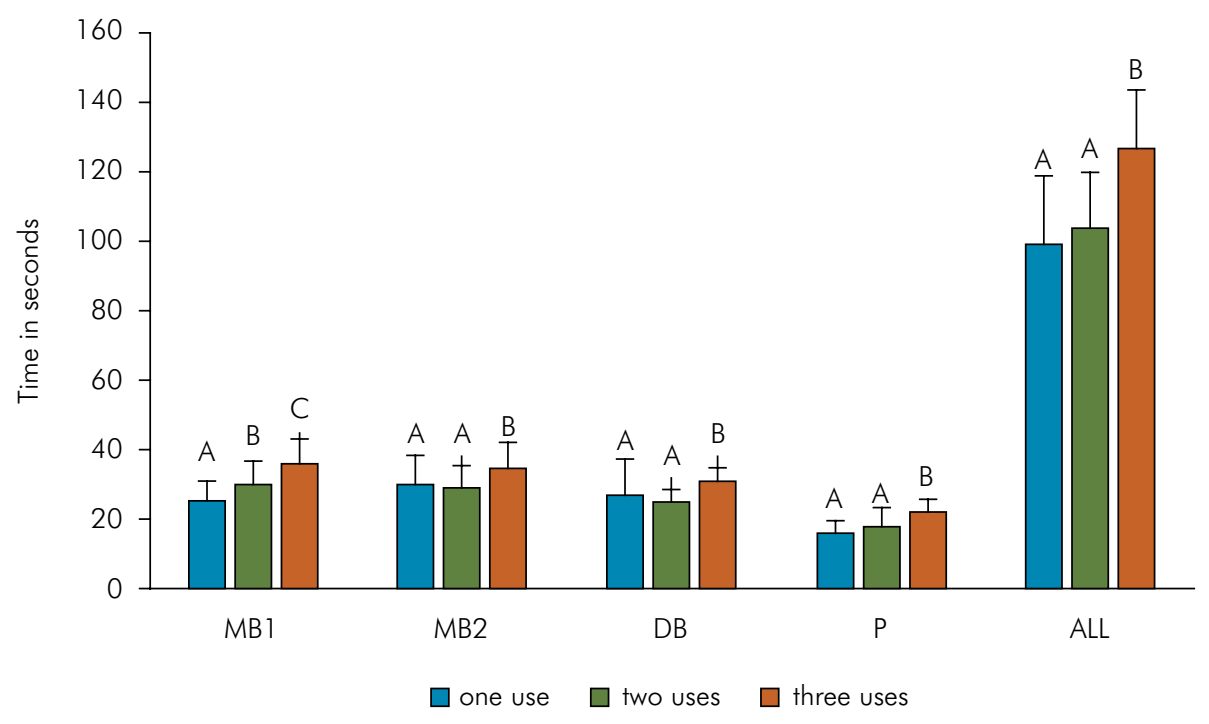

Figure 1. Time required preparing each root canal and the total tooth (used once, twice or three times). MB- Mesiobuccal canal, MB2 - Second mesiobuccal, DB - Distobuccal canal, and P - Palatal canal. 
Effects of clinical use of NiTi reciprocating instruments on cyclic and torsional resistance, and on roughness

Table. Mean and standard deviation of time to failure $(\mathrm{s})$, torque $(\mathrm{Ncm})$, angle of rotation $\left({ }^{\circ}\right)$ and surface roughness (Ra) of Reciproc instruments unused and with different number of times of clinical use.

\begin{tabular}{lcccc}
\hline Variable & $\begin{array}{c}\text { Time to failure }(\mathrm{s}) \\
(\mathrm{n}=10 \text { per group })\end{array}$ & Torque $(\mathrm{Ncm})$ & Angle of rotation $\left(^{\circ}\right)$ & Surface roughness $(\mathrm{Ra})$ \\
\cline { 3 - 5 } New instrument & $177 \pm 17^{\mathrm{A}}$ & $1.8 \pm 0.1^{\mathrm{A}}$ & $294 \pm 29^{\mathrm{A}}$ & $0.73 \pm 0.12^{\mathrm{A}}$ \\
Used once & $168 \pm 38^{\mathrm{A}}$ & $1.9 \pm 0.3^{\mathrm{A}}$ & $269 \pm 44^{\mathrm{A}}$ & $0.69 \pm 0.18^{\mathrm{A}}$ \\
Used twice & $157 \pm 34^{\mathrm{A}}$ & $1.7 \pm 0.2^{\mathrm{A}}$ & $298 \pm 32^{\mathrm{A}}$ & $0.40 \pm 0.05^{\mathrm{B}}$ \\
Used three times & $152 \pm 23^{\mathrm{A}}$ & $1.7 \pm 0.1^{\mathrm{A}}$ & $270 \pm 18^{\mathrm{A}}$ & $0.37 \pm 0.05^{\mathrm{B}}$ \\
\hline
\end{tabular}

Different superscript letters in the same column indicate statistic differences among the groups $(p<0.05)$.
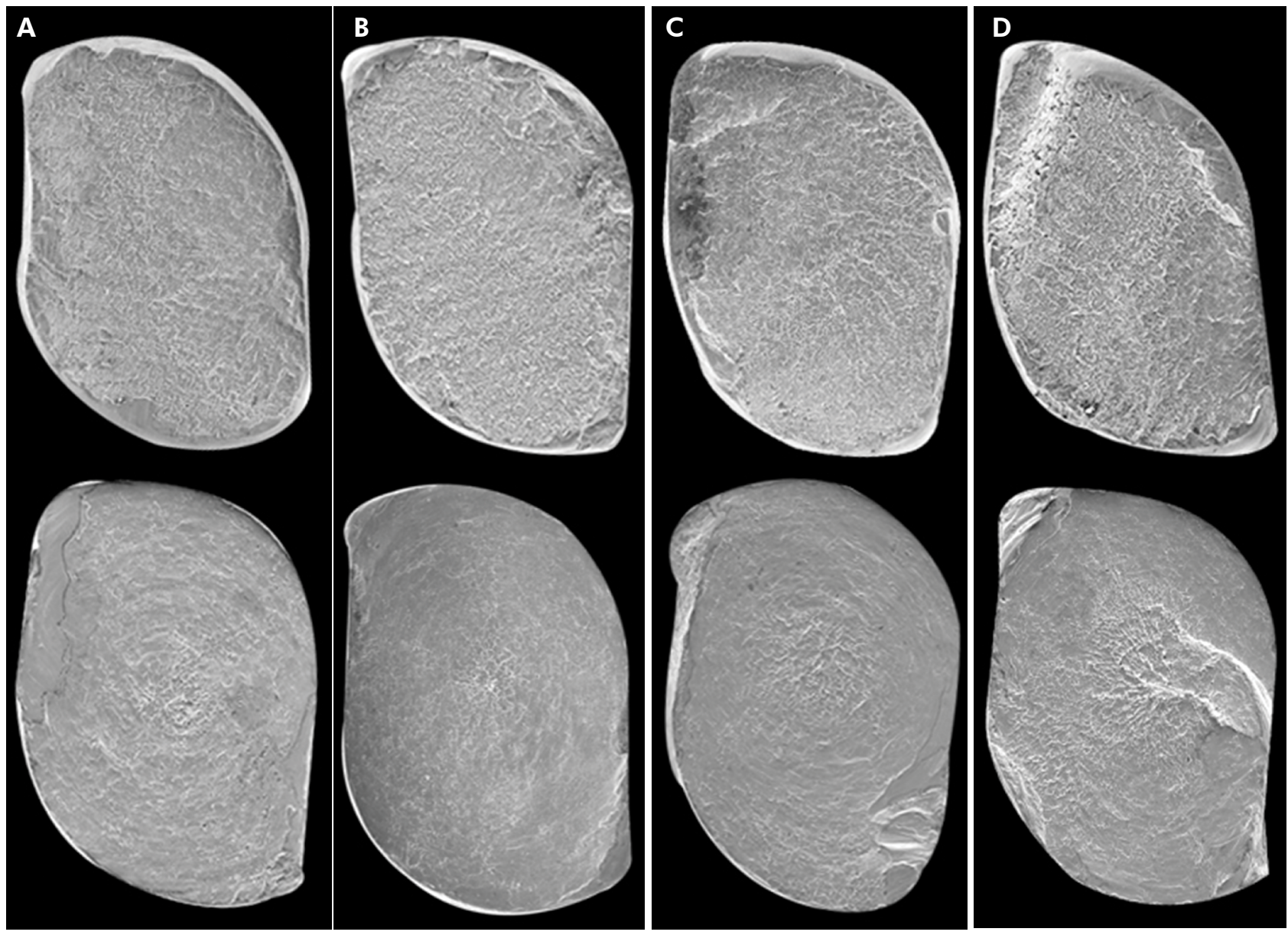

Figure 2. Scanning electron microscopic analysis of the tested instruments after cyclic fatigue (upside) and torsional resistance test (bottom). The images show $250 \times$ magnification. (A) new, unused instrument; (B) once-used instrument; (C) instrument used twice; and (D) instrument used three times.

device for cyclic fatigue testing, in order to make a direct comparison between new and used Reciproc instruments in a situation that can be standardized and reproduced. In our study, cyclic fatigue tests were performed at $37^{\circ} \mathrm{C}$, as suggested by previously published studies demonstrating that environmental temperature significantly influences the cyclic fatigue behavior of $\mathrm{NiTi}$ 

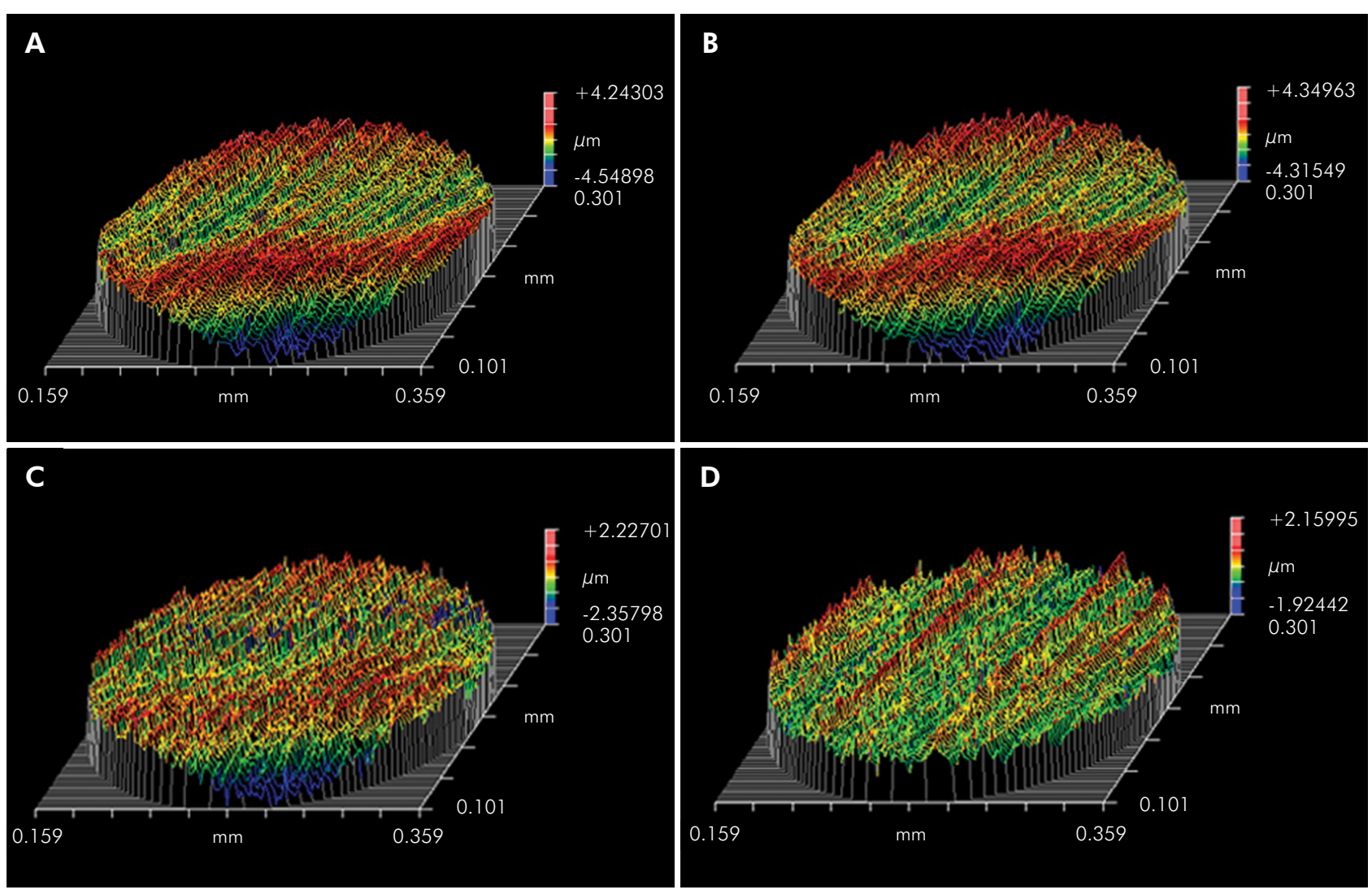

Figure 3. Instrument surface morphology obtained by interferometry. (A) new, unused instrument; (B) once-used instrument; (C) instrument used twice; and (D) instrument used three times.

instruments. ${ }^{17,18,19}$ The torsional resistance behavior test used in the present study was recommended by ISO 3630-1. ${ }^{13}$ Torsional resistance behavior was performed at room temperature $\left(21^{\circ} \mathrm{C}\right)$. The reason was based on a previously published study that showed no differences in the torsional behavior of conventional or martensitic NiTi instruments, whether performed at $21^{\circ} \mathrm{C}$ or $37^{\circ} \mathrm{C} .{ }^{15}$ In the present study, torque was applied counterclockwise, according to the direction of the Reciproc spiraling flutes. Moreover, continuous rotation was used to measure the ultimate torsional strength. It could be argued that this is not in accordance with the clinical use of Reciproc instruments. However, it is important to underscore that an instrument showing higher torque values during torsional tests should have better clinical durability against repetitive torsional stresses. In addition, asymmetrically reciprocating kinematics has a final rotary result, and is therefore vulnerable to torsional stress. It is important to point out that the final rotary result is much more complex than a simple rotary motion, as used in the torsional resistance test, thus representing a possible limitation of the method. The results of the present study also revealed that clinical use did not influence the cyclic fatigue or torsional resistance of the Reciproc instruments. Therefore, the first and second null hypotheses tested were accepted. Previous studies showed that cyclic fatigue ${ }^{20,21}$ and torsional resistance ${ }^{22}$ significantly declined after simulated clinical use, a result not in accordance with the present results. These differences could be explained mainly by two important improvements made in the Reciproc system. First, Reciproc is activated using reciprocating kinematics. This technique is known to improve the lifespan of endodontic instruments per se, ${ }^{5,8}$ since it minimizes the stress on the 
instrument by reversing the rotation direction, and maintains the instrument deformation below the pseudoelastic limit. Moreover, Reciproc instruments are manufactured with M-Wire NiTi alloy, which is more resistant to cyclic fatigue and torsional resistance than the conventional NiTi alloy.,14,23,24 It is noteworthy to mention that the Reciproc system tends to reduce the time to fracture after each clinical use of the instrument (Table). Although no statistical differences were observed between the tested groups, it can be inferred that the greater the number of times the instrument is used clinically, the shorter the time until it fractures from cyclic fatigue. Based on these results and in anticipation of further studies, it should be stressed that safety protocols for the reuse of NiTi endodontic instruments should be developed.

SEM has been widely used to examine changes in the surface of NiTi instruments after use. ${ }^{25,26}$ However, this method only provides $2 \mathrm{D}$ topographic images that preclude quantitative examination and statistical comparison. In contrast, surface roughness is evaluated using a profilometer of 3D images that enables quantitative data to be obtained. ${ }^{15,27}$ This is the reason why this method was chosen to evaluate how clinical use influences surface modification of Reciproc instruments. According to the results obtained in the present study, there was no difference in the surface roughness of new Reciproc instruments and Reciproc instruments used in one maxillary molar. However, groove depth was lower in Reciproc instruments after preparation of two or three maxillary molars. Therefore, the third null hypothesis was rejected. Several previous studies using an atomic force microscope (AFM) have demonstrated that clinical use might increase the surface porosity of an instrument. ${ }^{28,29}$ The AFM has a tip that is attracted or repulsed by the sample surface, unlike the roughness assessed by interferometry, which uses optical systems that completely exclude any physical contact. The differences in the findings for $\mathrm{AFM}^{28,29}$ and SEM ${ }^{25,26}$ can be attributed to the nature of the methods. It is reasonable to suppose that use of the instrument leads to wear of the finishing surface due to friction with dentin, thus reducing surface roughness.
Another aspect is that dentin can accumulate on surface defects even with ultrasonic cleaning, thus causing a smoother surface effect. ${ }^{30}$

Regarding the time used to prepare root canals, the results clearly indicate that more time was needed to complete root canal preparation during the third use. These results can be explained by the decrease in the cutting ability of Reciproc instruments after two clinical uses followed by two autoclave sterilization procedures. Although this increase in root canal preparation time did not affect the cyclic fatigue or the torsional resistance results, it may be the first sign of deterioration of the instrument, possibly related to a more imminent risk of instrument fracture. Thus, use of the instrument more than the 3 times tested in the present study would not seem advisable.

To the best of the authors' knowledge, this is the first study that evaluated cyclic fatigue, torsional resistance and roughness in a clinical scenario, in contrast to other studies that evaluated the properties in a simulated clinical setting. ${ }^{19,20,21}$ It is important to emphasize that, although root anatomy is very diverse, an effort was made to standardize the samples of this study, in order to isolate the variables of interest, and thus reduce the number of biases. The inclusion criteria used in the present study did not take into account more complex anatomies, such as sharp curvatures or long teeth. It might be difficult to correlate the findings of laboratory tests with a clinical situation, because of the number of variables acting together to result in the fracture of the instrument. Nevertheless, it is important to assess the mechanical properties of endodontic instruments in order to provide the clinician with valid and more conclusive information.

\section{Conclusion}

Based on the results of the present study, it can be concluded that the clinical use of Reciproc instruments increased preparation time and decreased instrument surface roughness. However, clinical use did not affect the cyclic fatigue and torsional resistance of Reciproc instruments. 


\section{References}

1. Sattapan B, Nervo GJ, Palamara JE, Messer HH. Defects in rotary nickel-titanium files after clinical use. J Endod. 2000 Mar;26(3):161-5. https://doi.org/10.1097/00004770-200003000-00008

2. Peters OA. Current challenges and concepts in the preparation of root canal systems: a review. J Endod. 2004 Aug;30(8):559-67. https://doi.org/10.1097/01.DON.0000129039.59003.9D

3. Gavini G, Santos MD, Caldeira CL, Machado ME, Freire LG, Iglecias EF, et al. Nickel-titanium instruments in endodontics: a concise review of the state of the art. Braz Oral Res. 2018 Oct;32 suppl 1:e67. https://doi.org/10.1590/1807-3107bor-2018.vol32.0067

4. Martins JNR, Silva EJNL, Marques D, Ginjeira A, Fernandes FMB, De Deus G, Versiani MA. Influence of kinematics on the cyclic fatigue resistance of replicalike and original brand rotary instruments. J Endod. 2020 Aug;46(8):1136-43. https://doi.org/10.1016/i.joen.2020.05.001

5. Yared G. Canal preparation using only one Ni-Ti rotary instrument: preliminary observations. Int Endod J. 2008 Apr;41(4):339-44. https://doi.org/10.1111/j.1365-2591.2007.01351.x

6. Kiefner P, Ban M, De-Deus $G$. Is the reciprocating movement per se able to improve the cyclic fatigue resistance of instruments? Int Endod J. 2014 May;47(5):430-6. https://doi.org/10.1111/iej.12166

7. Silva EJ, Vieira VT, Hecksher F, Oliveira MRS, Antunes HS, Moreira EJ. Cyclic fatigue using severely curved canals and torsional resistance of thermally treated reciprocating instruments. Clin Oral Investig. 2018 Sep;22(7):2633-8. https://doi.org/10.1007/s00784-018-2362-9

8. Zupanc J, Vahdat-Pajouh N, Schäfer E. New thermomechanically treated NiTi alloys - a review. Int Endod J. 2018 Oct;51(10):1088-103. https://doi.org/10.1111/iej.12924

9. Gambarini G, Rubini AG, Al Sudani D, Gergi R, Culla A, De Angelis F, et al. Influence of different angles of reciprocation on the cyclic fatigue of nickel-titanium endodontic instruments. J Endod. 2012 Oct;38(10):1408-11. https://doi.org/10.1016/i.joen.2012.05.019

10. De Deus G, Marins J, Silva EJ, Souza E, Belladonna FG, Reis C, et al. Accumulated hard tissue debris produced during reciprocating and rotary nickel-titanium canal preparation. J Endod. 2015 May;41(5):676-81. https://doi.org/10.1016/i.joen.2014.11.028

11. Bueno CS, Oliveira DP, Pelegrine RA, Fontana CE, Rocha DG, Bueno CE. Fracture incidence of waveone and reciproc files during root canal preparation of up to 3 posterior teeth: a prospective clinical study. J Endod. 2017 May;43(5):705-8. https://doi.org/10.1016/i.joen.2016.12.024

12. Generali L, Puddu P, Borghi A, Brancolini S, Lusvarghi L, Bolelli G, et al. Mechanical properties and metallurgical features of new and ex vivo used Reciproc Blue and Reciproc. Int Endod J. 2020 Feb;53(2):250-64. https://doi.org/10.1111/iej.13214

13. International Organization for Standardization - ISO. ISO 3630-1. Dental root canal instruments: part 1- files, reamers, barbed broaches, rasps, paste carriers, explorers and cotton broaches. Geneva: International Organization for Standardization; 1992.

14. Lopes HP, Gambarra-Soares T, Elias CN, Siqueira JF Jr, Inojosa IF, Lopes WS, et al. Comparison of the mechanical properties of rotary instruments made of conventional nickel-titanium wire, M-wire, or nickel-titanium alloy in R-phase. J Endod. 2013 Apr;39(4):516-20. https://doi.org/10.1016/i.joen.2012.12.006

15. Silva EJ, Giraldes JF, Lima CO, Vieira VT, Elias CN, Antunes HS. Influence of heat treatment on torsional resistance and surface roughness of nickel-titanium instruments. Int Endod J. 2019 Nov;52(11):1645-51. https://doi.org/10.1111/iej.13164

16. Plotino G, Grande NM, Porciani PF. Deformation and fracture incidence of Reciproc instruments: a clinical evaluation. Int Endod J. 2015 Feb;48(2):199-205. https://doi.org/10.1111/iej.12302

17. Grande NM, Plotino G, Silla E, Pedullà E, De Deus G, Gambarini G, et al. Environmental Temperature Drastically Affects Flexural Fatigue Resistance of Nickel-titanium Rotary Files. J Endod. 2017 Jul;43(7):1157-60. https://doi.org/10.1016/i.joen.2017.01.040

18. Yılmaz K, Uslu G, Gündoğar M, Özyürek T, Grande NM, Plotino G. Cyclic fatigue resistances of several nickel-titanium glide path rotary and reciprocating instruments at body temperature. Int Endod J. 2018 Aug;51(8):924-30. https://doi.org/10.1111/iej.12901

19. Ounsi HF, Salameh Z, AI-Shalan T, Ferrari M, Grandini S, Pashley DH, et al. Effect of clinical use on the cyclic fatigue resistance of ProTaper nickel-titanium rotary instruments. J Endod. 2007 Jun;33(6):737-41. https://doi.org/10.1016/i.joen.2007.03.006

20. Jamleh A, Yahata Y, Ebihara A, Atmeh AR, Bakhsh T, Suda H. Performance of NiTi endodontic instrument under different temperatures. Odontology. 2016 Sep;104(3):324-8. https://doi.org/10.1007/s10266-015-0214-5

21. Pessoa OF, Silva JM, Gavini G. Cyclic fatigue resistance of rotary NiTi instruments after simulated clinical use in curved root canals. Braz Dent J. 2013;24(2):117-20. https://doi.org/10.1590/0103-6440201302164

22. Bahia MG, Melo MC, Buono VT. Influence of simulated clinical use on the torsional behavior of nickel-titanium rotary endodontic instruments. Oral Surg Oral Med Oral Pathol Oral Radiol Endod. 2006 May;101(5):675-80. https://doi.org/10.1016/i.tripleo.2005.04.019

23. Gao Y, Gutmann JL, Wilkinson K, Maxwell R, Ammon D. Evaluation of the impact of raw materials on the fatigue and mechanical properties of ProFile Vortex rotary instruments. J Endod. 2012 Mar;38(3):398-401. https://doi.org/10.1016/i.joen.2011.11.004 
Effects of clinical use of NiTi reciprocating instruments on cyclic and torsional resistance, and on roughness

24. Pereira ES, Gomes RO, Leroy AM, Singh R, Peters OA, Bahia MG, et al. Mechanical behavior of M-Wire and conventional NiTi wire used to manufacture rotary endodontic instruments. Dent Mater. 2013 Dec;29(12):e318-24. https://doi.org/10.1016/i.dental.2013.10.004

25. Türker SA, Sağlam BC, Koçak MM, Koçak S. The effect of glide path on the surface quality of new and used rotary and reciprocating single files: OneShape versus WaveOne. Scanning. 2014 Nov-Dec;36(6):608-13. https://doi.org/10.1002/sca.21161

26. Caballero H, Rivera F, Salas H. Scanning electron microscopy of superficial defects in Twisted files and Reciproc nickel-titanium files after use in extracted molars. Int Endod J. 2015 Mar;48(3):229-35. https://doi.org/10.1111/iej.12304

27. Rodrigues CS, Vieira VT, Antunes HS, De Deus G, Elias CN, Moreira EJ, et al. Mechanical characteristics of counterfeit Reciproc instruments: a call for attention. Int Endod J. 2018 May;51(5):556-63. https://doi.org/10.1111/iej.12792

28. Inan U, Aydin C, Uzun O, Topuz O, Alacam T. Evaluation of the surface characteristics of used and new ProTaper Instruments: an atomic force microscopy study. J Endod. 2007 Nov;33(11):1334-7. https://doi.org/10.1016/i.joen.2007.07.014

29. Pirani C, Paolucci A, Ruggeri O, Bossù M, Polimeni A, Gatto MR, et al. Wear and metallographic analysis of WaveOne and reciproc NiTi instruments before and after three uses in root canals. Scanning. 2014 Sep-Oct;36(5):517-25. https://doi.org/10.1002/sca.21150

30. Alapati SB, Brantley WA, Svec TA, Powers JM, Mitchell JC. Scanning electron microscope observations of new and used nickel-titanium rotary files. J Endod. 2003 Oct;29(10):667-9. https://doi.org/10.1097/00004770-200310000-00014 